\title{
STUDY OF ALUMINUM MELT REFINING PROCESS EFFICIENCY DEPENDING ON IMPELLER
} WEAR

\author{
${ }^{1}$ Ladislav SOCHA, ${ }^{1}$ Karel GRYC, ${ }^{1}$ Jana SVIŽELOVÁ, ${ }^{2}$ Tomáš PRÁŠIL, ${ }^{2}$ Roman POSPÍŠIL, \\ ${ }^{2}$ Martin GRÁF \\ ${ }^{1}$ Institute of Technology and Business in České Budějovice, České Budějovice, Czech Republic, EU, \\ socha@mail.vstecb.cz, gryc@mail.vstecb.cz, svizelova@mail.vstecb.cz \\ ${ }^{2}$ MOTOR JIKOV Slévárna (Foundry) a.s., Die-casting Division, České Budějovice, Czech Republic, EU, \\ TPrasil@migroup.cz, RPospisil@misl.cz, MGraf@misl.cz
}

https://doi.org/10.37904/metal.2021.4256

\begin{abstract}
The Foundry Degassing Unit for aluminum melt refining uses graphite components which, due to the action of the melt, degrade and lose their original shape. The shape of the impeller can have a significant effect on the efficiency of refining. This paper presents the study of the aluminum melt refining process efficiency depending on the degree of impeller wear. Operational experiments were performed to map degassing efficiency in defined phases of the impeller life. The efficiency was assessed by the Dichte Index which represents the degree of degasification of the melt after refining. It turned out that the new impeller released moisture into the melt, resulting in reduced impeller efficiency. The impeller achieved more than $90 \%$ efficiency in the following stages of its life.
\end{abstract}

Keywords: Aluminum, aluminum refinement, FDU, impeller wear, Dichte Index

\section{INTRODUCTION}

Nowadays, FDU (Foundry Degassing Unit, see Figure 1) refining systems are largely used to refine aluminum alloys [1]. This unit is an automated metal treatment system for environmentally friendly degassing (hydrogen removal) and purification of aluminum alloys. FDU units utilize the principle of a blower with a patented impeller. The principle of refining consists in forcing an inert gas using a shaft with the impeller into the bottom part of the pan. The impeller divides the inert gas into fine bubbles and mixes them with the molten mass.

As mentioned above, one of the functions of the impeller is to disperse the argon flow into small bubbles [2,3]. The smaller the bubbles, the greater the overall specific surface area of the bubbles in the molten mass and thus the more intensive degassing is achieved $[4,1]$. Additionally, smaller bubbles exhibit a longer time of retention in the molten mass, thereby providing more opportunity for hydrogen to diffuse into the bubbles [5]. The degassing kinetics is also supported by the turbulent flow induced by the impeller. The turbulent flow ensures agitation of the molten mass; this accelerates hydrogen transport from the molten mass to the molten mass-bubble interface [6]. These hydrodynamic parameters can be modified by changing not only the rotation frequency, but also the shape and position of the impeller.

Clearly, the impeller is an important component that can have an impact on refining efficiency. The life of the impeller is very closely related to optimisation of the refining process. Particularly, impellers

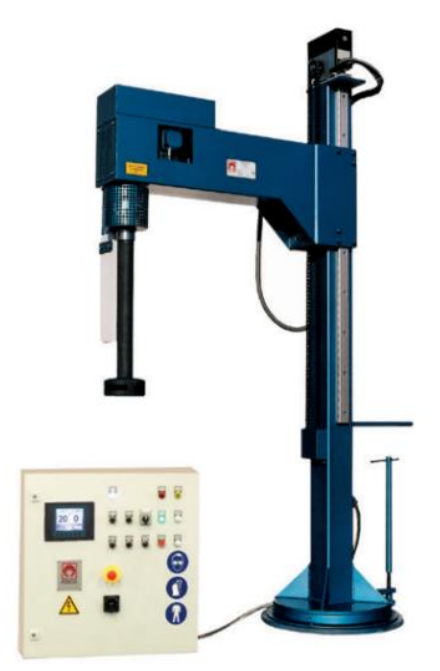

Figure 1 Foundry degassing unit [1] 
made of graphite tend to degrade in time due to oxidization at higher temperatures and abrasion. Scaling of graphite particles off the impeller has a negative impact on molten aluminum purity after the refining process. The loss of graphite has a negative impact, as well, as the impeller's shape changes due to abrasion and oxidization with an increasing number of performed cycles, which may have a negative effect on refining efficiency.

Based on the above, the idea was formulated to study the graphite impeller in various stages of life in order to describe any changes in efficiency of the refining process due to impeller wear. This paper summarizes the research methods and the results.

\section{TECHNOLOGICALPROCEDURE OF HIGH-PRESSURE CASTING PRODUCTION}

The molten aluminum alloy is made in the gas melting furnace STRIKO MH II-T 2000/1000. A preheated pan is used to transport the liquid metal. In the next step, refining is performed using a degassing unit where an inert gas (nitrogen under operating conditions) is blown into the molten mass using a graphite impeller. Very fine gas bubbles and intensive agitation of the molten mass ensure rapid and efficient degassing, removal of impurities and reduction of the content of non-metal inclusions. The molten mass is treated in the FDU unit ROTO-STATIV 1-5201 of FOSECOas illustrated in Figure 2. Technological parameters of the molten mass refining process for high-pressure casting are as follows:

$\checkmark \quad$ Degassing duration $\rightarrow$ refining for 3 minutes

$\checkmark \quad$ Rotation frequency of the impeller $\rightarrow 300$ to $350 \mathrm{rpm}$

$\checkmark \quad$ Nitrogen flow rate $\rightarrow 15$ to $17 \mathrm{l} \cdot \mathrm{min}^{-1}$

High-pressure casting using COLOSIO PFO1000 systems is the laststep. In this process, the molten alloy is injected into the cavity within a metal die using a high pressure, up to $250 \mathrm{MPa}$.

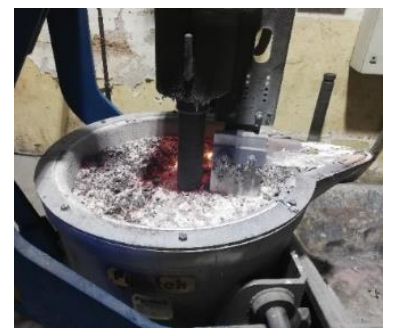

a) Course of the refining process

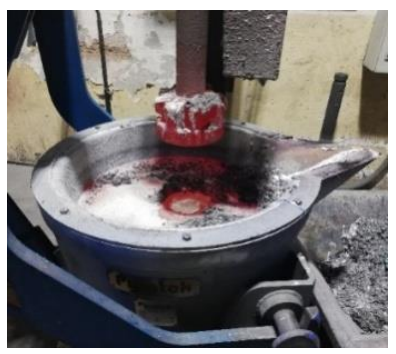

b) End of the refining process

Figure 2 Degassing FDU unit ROTOR-STATIV 1-5201

\section{OPERATING TESTS}

The presented research was focused on assessing refining efficiency at the $F D U$ unit with various degrees of wear of the graphite components using the following steps: $0 \%, 25 \%, 50 \%, 75 \%$ and $100 \%$. A standard impeller supplied by FOSECO, used for molten aluminum refining at the FDU unit of the Die-casting Division at MOTOR JIKOV Slévárna (Foundry) a.s., was chosen to test the efficiency under various degrees of wear. For the purpose of operating tests, technological parameters were defined for the refining process at the FDU unit; these are presented in Table $\mathbf{1}$ together with an illustration of the impeller.

Table 1 Settings of technological parameters of the impeller refining cycle

\begin{tabular}{|l|l|l|}
\hline \multicolumn{2}{|c|}{ Refining process parameters } & \multicolumn{2}{c|}{ Impeller illustration } \\
\hline Material & Graphite \\
\hline Refining duration & $180 \mathrm{~s}$ \\
\hline Rotation frequency & $350 \mathrm{rpm}$ \\
\cline { 1 - 2 } Nitrogen flow rate & $\begin{array}{l}17 / \mathrm{min}^{-} \\
1\end{array}$ \\
\hline Working height & $160 \mathrm{~mm}$ & \\
\hline
\end{tabular}


Impeller life stages were defined in advance for the purpose of its testing; the stages were gradually mapped by performing operating tests at MOTOR JIKOV Slévárna (Foundry) a.s. The life of the impeller was assessed according to the number of performed refining cycles at the $F D U$ unit $(1$ cycle $=1$ processed melt). According to information from the manufacturer and based on experience of the foundry technologists, the standard life of an impeller is approx. 1200 cycles. This value corresponded to $100 \%$ wear of the impeller. Other wear stages of the impeller were derived from its maximum life, i.e. the 1200 cycles. The operating tests and impeller wear values in individual experiment series are presented in Table 2. To give an idea of the wear degree, Figure 3 shows photographs of impellers with corresponding wear. As determined based on 3D scanning of three worn impellers, the material loss ranges between $22 \%$ to $27 \%$.

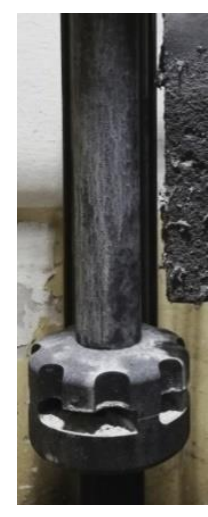

a) Wear $0 \%$

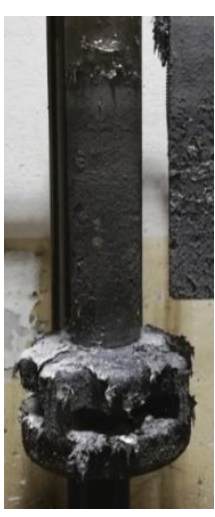

b) Wear $25 \%$

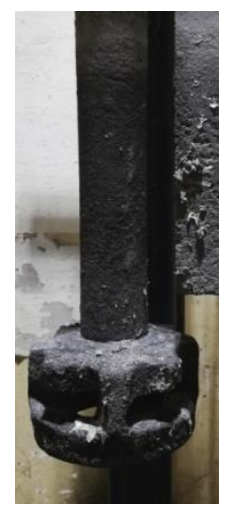

c) Wear $50 \%$

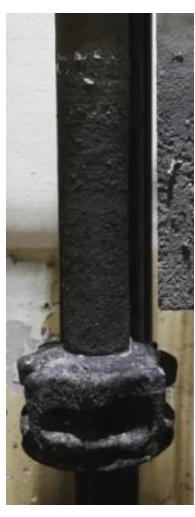

d) Wear $75 \%$

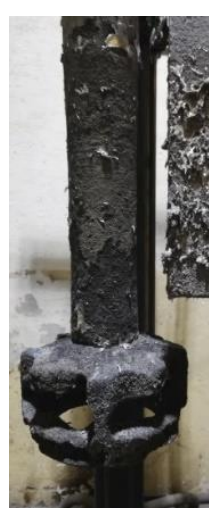

e) Wear $100 \%$

Figure 3 Illustration of gradual wear of the impeller and shaft

Table 2 Course of operating tests and the impeller wear values

\begin{tabular}{|c|c|c|}
\hline Experiment series & Impeller wear & Cycles \\
\hline I & $0 \%$ & $0 \times$ \\
\hline II & $25 \%$ & $360 \times$ \\
\hline III & $50 \%$ & $651 \times$ \\
\hline IV & $75 \%$ & $878 \times$ \\
\hline V & $100 \%$ & $1,152 \times$ \\
\hline
\end{tabular}

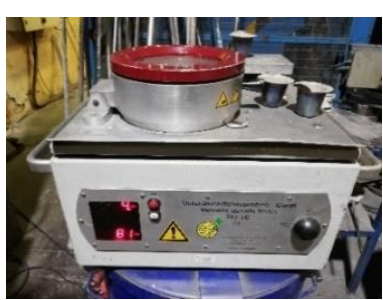

Figure 4 3VT LC system

Efficiency of the molten aluminum refining process was assessed by determining the hydrogen (gas) level in the molten mass before and after refining at the FDU unit. The gas content is usually determined using the socalled double weighing method that provides the Dichte Index (DI). The method is based on comparing the density of a molten mass sample solidified at atmospheric pressure and that of a sample solidified under partial vacuum. The 3VT LC system of mk AL-SCHMELZE-MESSTECHNIK was used in the operating experiments to evaluate the gas level (see Figure 4). Thus, samples were taken from each melt and the Dichte Index (DI) value was determined for each sample in order to assess the molten mass gas content. At many aluminum alloy foundries, the complex method of $D /$ determination is implemented only partially: instead of performing the entire calculation of $D I$ in the scope of operating tests of the aluminum alloy samples, it is only checked whether the density value of samples solidified under partial vacuum exceeds $2.6 \mathrm{~g}_{\mathrm{cm}} \mathrm{cm}^{-3}$. In the course of evaluating the results, attention was focused on this parameter, as well. An illustration of samples intended for gas content analysis, collected before $\left(F D U_{\text {start }}\right)$ and after refining $\left(F D U_{\text {tinish }}\right)$, is shown in Figure 5. 

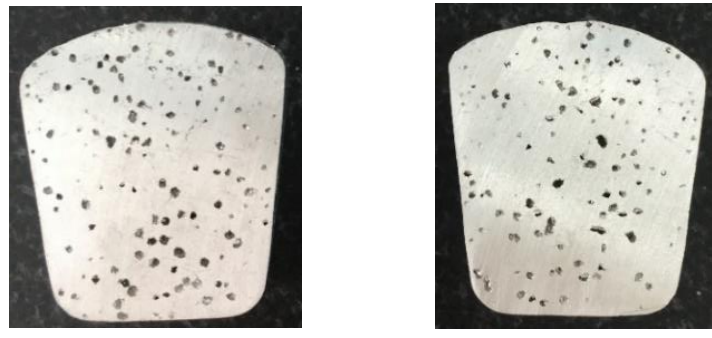

a) $F D U_{\text {start }} \rightarrow D I=10.79 \% ; \rho_{\text {start }}=2.3935 \mathrm{~g} \cdot \mathrm{cm}^{-3}$
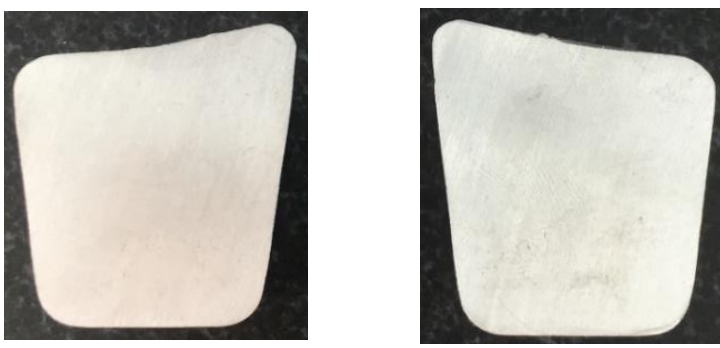

b) $F D U_{\text {finish }} \rightarrow D I=0.62 \%$; $\rho_{\text {finish }}=2.6875 \mathrm{~g} \cdot \mathrm{cm}^{-3}$

Figure 5 Illustration of samples used to determine the gas content

\section{RESULTS AND DISCUSSION}

The Dichte Index values achieved before ( $\left.F D U_{\text {start }}\right)$ and after the molten mass refining process $\left(F D U_{\text {inish }}\right)$ are plotted in Figure 6. Clearly, the molten mass contains an increased amount of hydrogen before refining. This fact is supported by higher $D I$ mean values at $F D U_{\text {start }}$ that range between $10.97 \%$ to $8.96 \%$. In the course of refining, the hydrogen content in the molten mass decreased, which was manifested by a $D /$ reduction to the mean values of $3.23 \%$ to $0.38 \%$. As illustrated by Figure 6 , a less significant decrease of the $D /$ value was achieved after refining ( $\left.F D U_{\text {finish }}\right)$ in the case of the impeller $0 \%$ wear series. As regards this experiment series, a higher value of $D I$ can be attributed to impeller moisture that is released into the molten mass at higher temperatures and increases the hydrogen content.
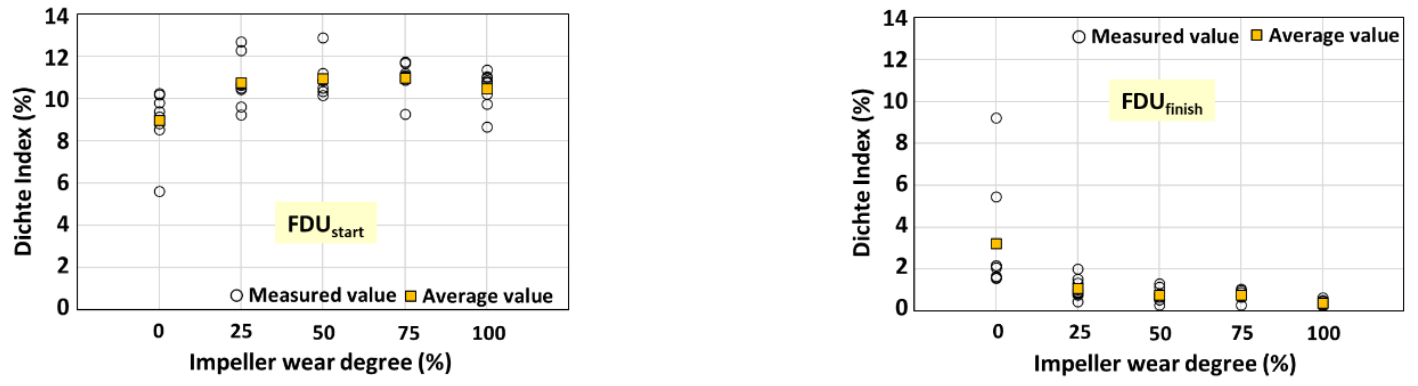

a) Comparison of achieved Dichte Index values $\rightarrow D I$
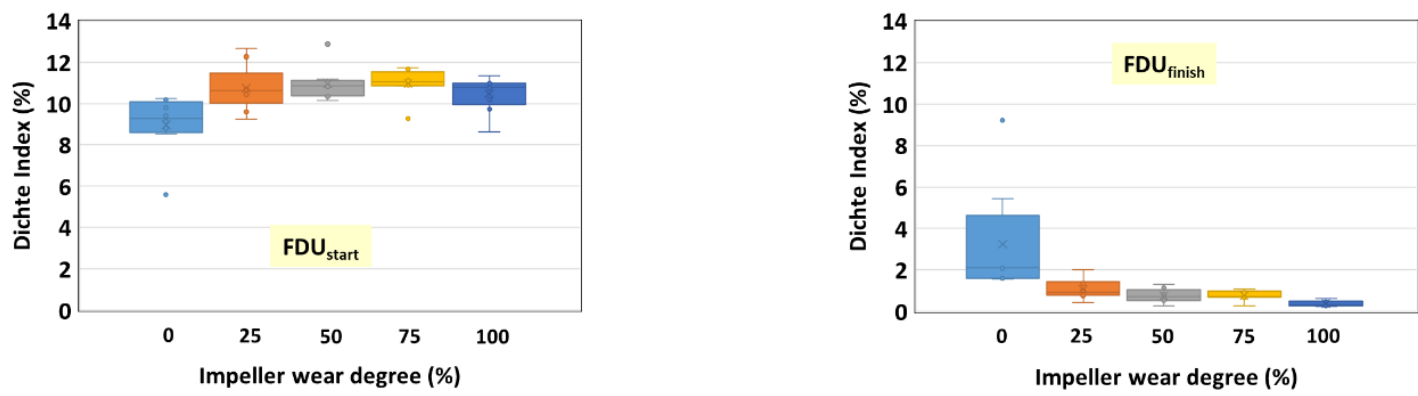

b) Comparison of achieved Dichte Index values $\rightarrow$ DI using the box plot

Figure 6 Dichte Index $(D I)$ results for various impeller wear degrees

Density of samples solidified under vacuum $\rho_{\text {sam,vac }}$ was another one of the evaluated parameters (see Figure 7). As can be observed, $\rho_{\text {sam,vac }}<2.6 \mathrm{~g} . \mathrm{cm}^{-3}$ for all collected samples before refining ( $F D U_{\text {start). }}$.

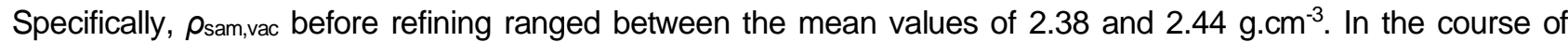

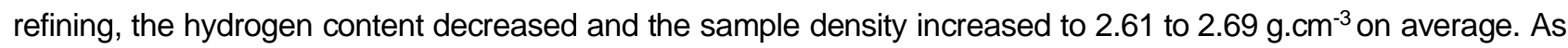
regards the $25 \%$ to $100 \%$ wear series, the density of all samples exceeded $2.6 \mathrm{~g} . \mathrm{cm}^{-3}$ and thus it can be stated that 
the molten mass was sufficiently degassed. An increased amount of hydrogen could be observed in the $0 \%$ wear series samples again. Density values of this series are low, and samples whose density did not reach the limit value of $2.6 \mathrm{~g} . \mathrm{cm}^{-3}$ could also be identified.
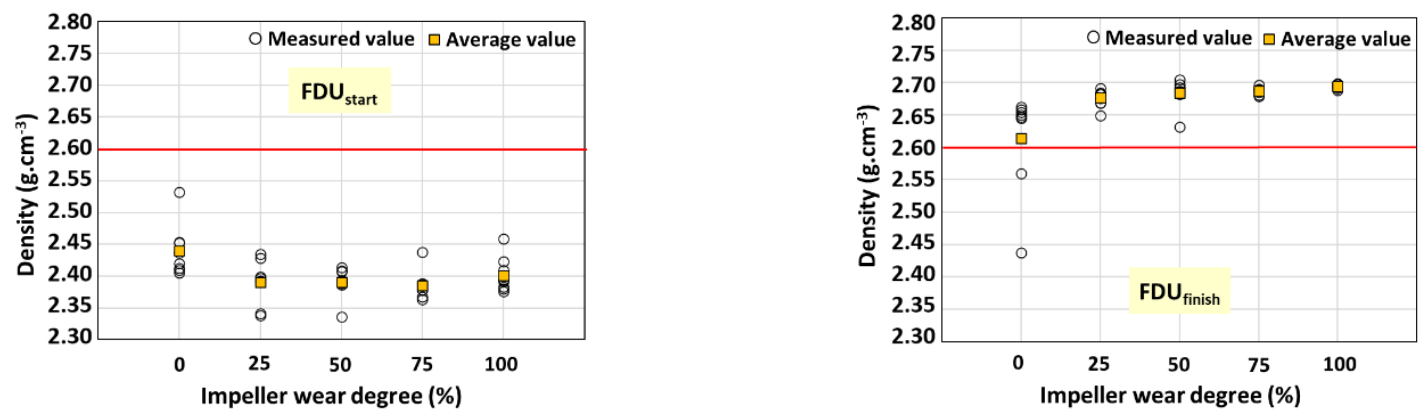

a) Comparison of achieved sample density values $\rightarrow \rho_{\text {sam,vac }}$
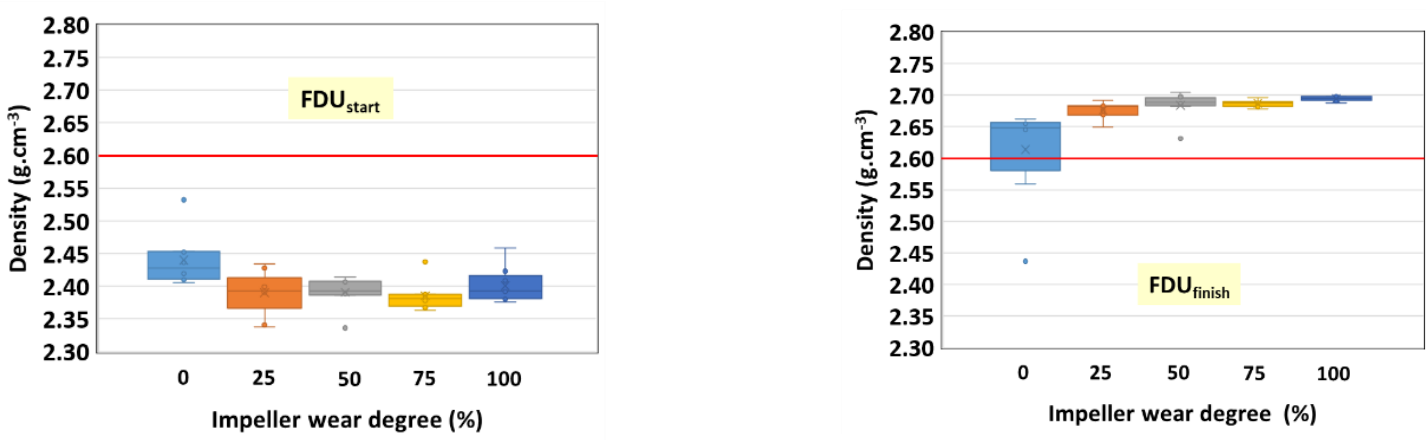

b) Comparison of achieved sample density values $\rightarrow \rho_{\text {sam, vac }}$ using the box plot

Figure 7 Sample density $\rho_{\text {sam,vac }}$ at various impeller wear degrees

The graph shown in Figure 8, also based on $D /$ results, shows percentage reduction of the Dichte Index value after refining $\left(F D U_{\text {tinish }}\right)$ with respect to its initial value $\left(F D U_{\text {start }}\right)$. For the research purposes, this percentage value was identified as molten aluminum refining efficiency at the $F D U$ unit.

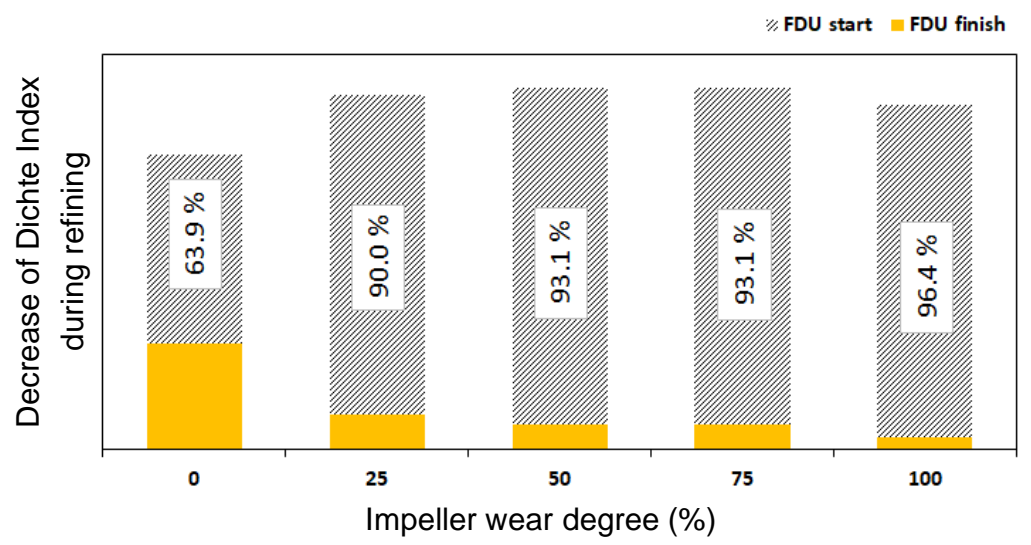

Figure 8 Percentage impeller efficiency in the course of its life

As clearly follows from Figure 8, the impeller exhibits refining efficiency over $90 \%$ for melt series with $25 \%$ to $100 \%$ wear. For the series with $0 \%$ wear, impeller A reached $63.9 \%$ efficiency. Such a low value was caused by the above mentioned moisture of the new impeller that results in hydrogen release into the molten mass during the refining process. Across individual series of impeller $A$, an interesting trend in $D /$ values achieved 
after refining was also observed - refining efficiency of the molten aluminum increased together with increasing wear.

\section{CONCLUSIONS}

The paper describes the study of $F D U$ refining efficiency depending on impeller wear. Operating tests were performed for this purpose at the Die-casting Division of MOTOR JIKOV Slévárna (Foundry) a.s., focused on determining the hydrogen content in molten aluminum. The following conclusions were made based on the test results:

$\checkmark \quad$ Considerable wear occurs while the impeller is used at the FDU refining unit. An impeller with 100\% wear showed an almost complete loss of its original shape.

$\checkmark \quad$ Evaluation of the operating tests revealed problems with moisture when new graphite impellers are used with $0 \%$ wear; this resulted in insufficient degassing of the molten mass. The molten mass thus failed to reach the determined quality level, which was negatively reflected in the observed parameters. Additionally, degassing efficiency was only $63.9 \%$. The problem with moisture of graphite components with $0 \%$ wear can be minimised by their preheating.

$\checkmark \quad$ Other series with $25 \%$ to $100 \%$ wear reached observed parameter values that clearly indicated a high efficiency of the refining process. In all these series, degassing efficiency was $90 \%$ at the minimum.

$\checkmark \quad$ Across individual series, an interesting trend in degassing efficiency was also observed. Degassing efficiency of the molten aluminum increased with increasing wear of the impeller. However, further study is needed to confirm this finding.

\section{ACKNOWLEDGEMENTS}

The paper was prepared under the support of the Technology Agency of the Czech Republic within the scope of the EPSILON programme, as part of projects Reg. No. TH04010449 "Research and development of refining technologies for increasing of quality of aluminum alloys for high-performance quality castings".

\section{REFERENCES}

[1] FDU Foundry Degassing Unit. Vesuvius: Melt treatment products for aluminum, copper, magnesium and zinc alloys [online]. [cit. 2021-6-4]. Available from:

https://www.vesuvius.com/content/dam/vesuvius/corporate/Our-solutions/our-solutions-masterenglish/foundry/non-ferrous-foundry/melt-treatment/brochures/FDU-e.pdf.downloadasset.pdf

[2] GOMÉZ, E.R., ZENIT, R., RIVERA, C.G. et. al. Mathematical modeling of fluid flow in a water physical model of an aluminum degassing ladle equipped with an impeller-injector. Metallurgical and Materials Transactions $B$. [online]. 2013, vol. 44B, pp. 423-435. Available from: https://doi.org/10.1007/s11663-012-9774-8.

[3] HERNÁNDEZ-HERNÁNDEZ, M., CAMACHO-MARTíNEZ, J.L., GONZÁLEZ-RIVERA, C. et al. Impeller design assisted by physical modeling and pilot plant trials. Journal of Materials Processing Technology. [online]. 2016, vol. 236, pp. 1-8. Available from: https://doi.org/10.1016/j.jmatprotec.2016.04.031.

[4] ROUČKA, J. Metallurgy of non-ferrous alloys, Brno: Academic publishing house, 2004.

[5] WARKE, V. S., TRYGGVASON, G., MAKHLOUF, M.M. Mathematical modeling and computer simulation of molten metal cleansing by the rotating impeller degasser: Part I. Fluid flow. Journal of Materials Processing Technology. [online]. 2005, vol. 168, no. 1, pp. 112-118. Available from: https://doi.org/10.1016/i.jmatprotec.2004.10.017.

[6] MYSLIVEC, T. Physico-chemical bases of steel industry. Prague: SNTL, 1971. 